\title{
The Carry-Over of Mycotoxins in Products of Animal Origin with Special Regard to Its Implications for the European Food Safety Legislation
}

\author{
Inger Völkel, Eva Schröer-Merker, Claus-Peter Czerny
}

Department of Animal Sciences, Division Microbiology and Animal Hygiene, Georg-August University, Göttingen, Germany. Email: cczerny@gwdg.de

Received June $14^{\text {th }}, 2011$; revised July $29^{\text {th }}, 2011$; accepted August $6^{\text {th }}, 2011$.

\begin{abstract}
At present, carry-over research in mycotoxins experiences a change in focus. We reviewed the state-of-the-art knowledge regarding carry-over in aflatoxins, ochratoxin A, Fusarium toxins, patulin, ergot and citrinin. The common cooccurrence of mycotoxins demands for employment of multi-toxin analysis and poses a new challenge in reliable health hazard assessment. Synergies in adverse mycotoxin effects call for a revision of various guidance levels in feed. We found a lack of risk assessment regarding carry-over of rare mycotoxins and metabolites usually considered negligible.
\end{abstract}

Keywords: Carry-Over Research, Mycotoxins, Co-Occurrence, Synergistic Effects, Food Legislation, Threshold Limits, Compliance

\section{Introduction}

Mycotoxins can be seen as natural contaminants which can occur in food, originating from the environment, processing or packaging. Despite being classified as categorically undesirable, their occurrence usually is not completely preventable even when using Good Manufacturing Practice. Even though, up to a certain level they might not pose any direct health concern to the consumer, they are still adding to the overall exposure. Today, mycotoxins are believed to play an important role in food safety and hygiene next to viral and bacterial agents.

The term carry-over denotes the passage of undesired compounds from contaminated feed into food of animal origin. Essential topics in carry-over research include reasons and detailed mechanisms of this process, carryover-ratios and resulting human health risks. In Germany, research on this topic began in 1974, when the German Agricultural Ministry established a scientific task force in order to work on carry-over of heavy metals. Amended by research on the carry-over of lead, the agenda was extended continuously, and during the 1980ies, herbicide residues, dioxins and organic-chlorine-compounds were added for hazard risk assessment. Since the very beginning, questions like contamination levels of home-grown and imported feed as well as the impact of feeding technique were addressed. Albeit aflatoxins had been examined since 1981, they continued to stay in focus for a long time apart from few studies on ochratoxin A and some Fusarium toxins. It was not until the beginning of the 1990s that other groups of mycotoxins were included in the studies.

Today, prevention and control of food contamination seem to remain difficult despite of combined international research efforts in the field of mycotoxins. Years of research not only have resulted in a basic understanding of fungal metabolism, but have also revealed the complexity of interactions between fungi, plants and mammals. Details of mycotoxin transfer have not been illuminated completely yet and considerations of risk assessment differ among scientists.

Apart from the minor molecular structure of mycotoxin compounds numerous endogenous host factors will strongly influence biotransformation and may result in a varying extent of deposition and accumulation in animal tissue or in an enhanced excretion via milk. At the moment, only a few groups of mycotoxins frequently seen in agricultural commodities are regulated by law within the European Union. Statutory limit values concerning food and animal feed are set for aflatoxins (AF), 
ochratoxin A (OTA), zearalenone (ZEA), deoxynivalenol (DON), patulin, and fumonisins. Statutory regulations with regard to HT-2, T-2 and ergot alkaloids are under discussion and are expected to follow soon.

This review summarizes the state-of-the-art carry-over research on mycotoxins in common livestock species. The first part introduces in detail each of these mycotoxins by presenting basic data including natural occurrence, adverse health effects, biotransformation, known data of carry-over to livestock animals and statutory limits set for feed or food stuffs. The second part not only evaluates carry-over study results, but critically deals with current mycotoxin feed and food legislation summarizing latest research achievements in the fields of bioavailability, biotransformation and synergistic toxin interactions, and pointing out weakpoints in current diagnostic tools and surveillance programmes.

\section{Mycotoxins Covered by the EU Legislation}

\subsection{Aflatoxins}

\subsubsection{Fungal Sources, Importance and Occurrence}

Feed is frequently contaminated with Aspergillus flavus or Aspergillus parasiticus during storage [1], but there is evidence that infestation of grain may also occur prior to harvest [2]. Environmental conditions conducive to $A s-$ pergillus moulds are presented at daytime temperatures of about $25^{\circ} \mathrm{C}-40^{\circ} \mathrm{C}$, while toxin production is enforced at temperatures ranging from $20^{\circ} \mathrm{C}$ to $30^{\circ} \mathrm{C}$. That is why aflatoxins usually are declared imported toxins within Central European countries faced to moderate climatic conditions. According to their growing regions, mainly pistachios, peanuts, hazelnuts, Brazil nuts, almonds, rice, sorghum, dried fruit and spices are agricultural commodities high at risk [3]. The frequent occurrence of aflatoxins in oilseeds and grain, especially in maize, not only poses a direct hazard to human consumption [1], but is also closely connected to the occurrence of aflatoxins in milk [4] and edible animal tissues.

\subsubsection{Aflatoxin Biotransformation}

The term aflatoxin (AF) has been derived from Aspergillus flavus, the fungi species it was first detected in. Aflatoxin variants are named according to their blue or green fluorescence behaviour in thin layer chromatography and their natural occurrence in milk (B1, B2, G1, G2, M1, M2) [5]. Aflatoxin B1, the parent toxin of M1 and M2, is considered the most frequent and hazardous aflatoxin and is regulated for feed in many countries worldwide. M1 and M2 are of special interest with regard to carry-over, since they can be excreted via milk. Biotransformation is mainly done on hepatic level, where microsomal cytochromes P450 turn B1 into the minor toxic M1 [6].
B1 can also be metabolised by reduction via NADPHdependent cytosolic enzymes resulting in aflatoxicol. Since this reaction is reversible, aflatoxicol can be considered as a non-detoxified and hazardous storage form, showing a toxicity and mutagenic potency equal to B1. Aflatoxicol might also be produced by ruminant microbes [7]. In mammalians, biotransformation can also result in the formation of highly reactive AFB1-epoxide, being reputed for its cancerogenity. Since this metabolite can be inactivated by glutathione (GSH) S-transferase, its detoxification pathway is highly important in several species and might mediate species resistance to AFB1 due to the protective effect of AFB1-GSH. Further detoxification might be mediated via conjugation with sulfates and glucuronic acid [8]. The total metabolism of AFB1, with special regard to the endogenous balance between activation and detoxification pathways, as well as the repair of genetic damages induced by the mycotoxin can be considered to be important criteria in species sensitivity [9].

\subsubsection{Adverse Health Effects in Humans and Animals} Aflatoxins can be considered the best investigated extrolites of micromycota. Increased attention is paid not only due to their widespread occurrence in staple foods and feeds but also because of their toxicity and cancerogenity. Toxic health effects might either be acute or chronic, predominantly influenced by the dose and duration of exposure. Apart from aflatoxicosis in humans, cattle, pigs and poultry are the farm animals that are primarily affected. AFB1 causes severe liver damages including hemorrhagic necrosis, fatty infiltration and bile duct proliferation $[2,10]$. Although a 10 -fold variation in species'susceptibility to the acute effects of AFB1 is documented, any species can be considered as totally resistant [9].

Apart from carcinogenic properties, aflatoxins are both mutagenic and teratogenic. Tumours due to aflatoxins can mainly be found in the liver, forming hepatocellular carcinoma, but may also occur in other organs. Epidemiological data support the hypothesis that, besides Hepatitis A viral infection, dietary AFB poses an important risk co-factor for human hepatocellular carcinoma (HCC).

\subsubsection{Carry-Over of Aflatoxins in Different Livestock Species}

With respect to the transfer into animal-derived products, especially B1, because of its prevalence and toxicity, as well as its metabolite M1 are of major importance. Evidence of carry-over due to aflatoxins has been found so far in milk, porcine tissue and eggs.

Several cases of carry-over in swine have been reported for aflatoxin B. It may occur in liver, muscles, 
kidneys and adipose. The addition of chemicals such as aluminosilicate sorbents to the fodder can decrease the amount of aflatoxin M1 detectable in liver, kidney and muscle tissue, whereas the amount of aflatoxin B1 only decreases in muscle tissue, but not in liver or kidneys [11].

In poultry, aflatoxin residues were found in eggs of young laying hens fed with diets of $500 \mathrm{mg} \cdot \mathrm{kg}^{-1}$ for seven weeks [12]. The aflatoxin B1 level within eggs ranged from $0.05-0.16 \mu \mathrm{g} \cdot \mathrm{kg}^{-1}$ (mean: $0.10 \mu \mathrm{g} \cdot \mathrm{kg}^{-1}$ ) and the carry-over ratio was calculated to be $0.02 \%$. This transfer could not be verified in a further study. In this four-week experiment, no residues of B1 or M1 were found in 69 laying hens after a daily B1 intake of 2.5 $\mathrm{mg} \cdot \mathrm{kg}^{-1}$, using a detection limit of $0.01 \mu \mathrm{g} \cdot \mathrm{kg}^{-1}$. Instead, negative influences on shell weight and yolk colour were observed [13]. The same study reported a carry-over of AFB1 into poultry tissue resulting in an intrahepatic concentration of $4.13 \mu \mathrm{g} \cdot \mathrm{kg}^{-1}$. The use of mannanoligosaccharides in the feed ration seemed to have a toxinabsorbing effect. A further study compared the transfer of aflatoxin B to laying ducks, hens, quails and broiler chickens [14]. The diet fed over a period of seven days included a toxin concentration of $3 \mathrm{mg} \cdot \mathrm{kg}^{-1}$. Quails showed the highest carry-over ratio to the liver with a value of $0.26 \%$ whereas the ratio in the liver of other poultry production groups was significantly lower $(0.017 \%)$. This result was confirmed by a feeding experiment of 42 days [15], where the administration of $1 \mathrm{mg} \mathrm{AFB1} / \mathrm{kg}$ feed resulted in hepatic AFB1 residuals at a level of $0.166 \mu \mathrm{g} \cdot \mathrm{kg}^{-1}$, forming a carry-over ratio of 0.016 . With regard to chicken eggs, Bintvihok et al. (2002) showed a ratio of $0.021 \%$ for yolk, and $0.026 \%$ for albumen, respectively [14].

Recently, carry-over of aflatoxins into eggs was found in a 60 days trial with naturally contaminated feed [16]. Egg production and weight were not influenced in a negative way, although, starting at a mycotoxin load of $50 \mu \mathrm{g} \cdot \mathrm{kg}^{-1}$ feed, the feed intake dropped. AFB1 was detected in eggs, values ranging from 0.02 to $0.09 \mu \mathrm{g} \cdot \mathrm{kg}^{-1}$.

The most important mycotoxin with regard to carryover in milk is aflatoxin M. AFM1 and M2 derive of the parent toxins B1 and B2 from which they are initialized by hydroxylation. They frequently occur in milk of dairy ruminants fed on contaminated supplies, but might also pose a risk to infant health being excreted via human breast milk. There is evidence for a seasonal distribution pattern in contamination [17]. Factors influencing the prevalence of carry-over include milk yield, feed consumption, the ratio of concentrated feed included in the diet, but also the geographical origin and harvest time of components used in concentrates [4] as well as feeding practice [18-20]. Battacone et al. (2003) reported an oscillating course of AFM1 excretion in milk [21]. After six hours, the toxin was detectable for the first time. Peaks of excretion could be observed after $24 \mathrm{~h}$ and 48 h. Continuing an identical daily exposure, a toxin accumulation in milk could be seen for several days before finally achieving a steady-state [21,22]. Secretion toxicokinetics are linearly dependent on the toxin intake while the toxin clearance is usually finished three days after withdrawal of the contaminated diet. The ratio between ingested and excreted aflatoxin seen in ruminants usually is $1 \%-3 \%$, but can reach $6 \%$ presuming worstcase scenarios [23]. High levels of variation can be observed from animal to animal, day to day, milking to milking and species to species. The carry-over ratio is not directly dependent on the doses administered albeit the absolute amount of M1 excreted is influenced by the AFB1 intake per $\mathrm{kg}$ of bodyweight [6,21]. Battacone et al. (2009) used a diet contaminated with up to $5 \mu \mathrm{g}$ AFB1 $/ \mathrm{kg}$ feed which resulted in $79.3 \mathrm{ng} \cdot \mathrm{kg}^{-1}$ milk [22]. The carry-over ratio ranged from $1.3 \%-2.9 \%$. The higher values in comparison to previous studies were obviously due to the use of naturally contaminated feed providing an additional background exposure [16,21]. Sugiyama et al. (2008) gave an interesting overview regarding naturally contaminated milk in Japan [4]. The study showed that the contamination levels of imported US-corn used in concentrates were up to $18 \mu \mathrm{g} \cdot \mathrm{kg}^{-1}$ in some months, resulting in average aflatoxin milk levels of $5-15 \mathrm{ng} \cdot \mathrm{L}^{-1}$.

Carry-over of aflatoxin into milk can be reduced by in vivo chemisorption [24]. In a special feeding trial composed by Harvey et al. (1991), dairy cows were fed diets contaminated with 100 and $200 \mu \mathrm{g} \mathrm{AF} / \mathrm{kg}$ [25]. A total carry-over of $0.91 \mu \mathrm{g}$ and $1.85 \mu \mathrm{g}$ in milk was observed. The use of a high-affinity sorbent compound succeeded in decreasing the carry-over, the proportion ( $24 \%$ - $44 \%)$ directly depending on the aflatoxin level in feed as well as on the sorbent concentration used within the trial.

\subsubsection{Limits Set for Aflatoxins in Feed Stuffs, Food, and Human Intake}

In Germany, the aflatoxin-regulation has been in force since 1977, underlining the national importance of these mycotoxins. Due to its cancerogenity, the uptake of aflatoxins by food should be as low as possible. This is the reason why, within the EU, no threshold limit concerning the tolerable daily intake in humans has been established. The aflatoxin legislation is intended to implement the ALARA principle (As Low As Reasonable Achievable), especially regarding juvenile consumers. While most countries have adopted the international AFM maximum level proposed by the WHO $(0.500 \mu \mathrm{g}$ AFM $1 / \mathrm{kg})$, the European Regulation (EC) No.1881/2006 declares a limit of $0.050 \mu \mathrm{g}$ AFM1 $/ \mathrm{kg}$ milk [26]. In baby-food including 
infant formula, even stricter limits were declared $(0.025$ $\left.\mu \mathrm{g} \cdot \mathrm{kg}^{-1}\right)$. In Germany, the national regulation on foods for specific dietary use narrows the maximum quantity allowed in dietetic baby food to $0.010 \mu \mathrm{g} \cdot \mathrm{kg}^{-1}$ [27].

Worldwide limitations set for aflatoxin content in animal feed vary depending on the livestock species, age- or production group as well as on the feedstuff affected. In the EU, maximum feed levels defined by national regulations range from $0.005 \mathrm{mg}-0.020 \mathrm{mg}$ AFB $1 / \mathrm{kg}$ feed (assuming dry matter contents of $88 \%$ ).

\subsection{Ochratoxin A}

\subsubsection{Fungal Sources and Affected Aliments}

Apart from aflatoxins, ochratoxin A (OTA) is the most important investigated mycotoxin with regard to carryover. OTA is produced by members of the genus Aspergillus (A. ochraceus, A. carbonarius) and Penicillium ( $P$. verrucosum). A minor toxic but co-occurring metabolite is the non-chlorinated analogue ochratoxin B. Invasion with ochratoxin-producing fungi has been observed worldwide. Contaminated foodstuffs involve grapes, wine, wine fruits, cereals, coffee, cocoa, edible nuts, pulses, beer and spices. Penicillium verrucosum is mainly responsible for grain infestation in cooler regions $[28,29]$. Despite toxin production may occur over a wide temperature range, optimal conditions for ochratoxin production are given by a temperature range between $20^{\circ} \mathrm{C}$ $25^{\circ} \mathrm{C}$ and a crop moisture content of at least $16 \%$.

\subsubsection{Adverse Health Effects in Humans and Animals}

Ochratoxin A is considered to be highly nephrotoxic. When confronted with concentrations as low as 200 $\mu \mathrm{g} \cdot \mathrm{kg}^{-1} \mathrm{BW}$, a progressive nephropathy without renal failure could be seen in pigs [28]. Due to their rumen microbes, ruminants are able to tolerate a daily OTA uptake up to $100 \mathrm{mg} /$ cattle/day, as reported by DFG [30]. Despite there is evidence that ochratoxin A primarily elicits renal cancer in rodents, this could not be verified for humans. Therefore OTA was only classified as possibly carcinogenic to humans (group 2B) by the International Agency for Research on Cancer (IARC) in 1993, even though a context with Balkan Endemic Nephropathy (BEN) or Urinary Tract Tumours (UTT) was discussed.

\subsubsection{OTA Biotransfomation}

Due to its extended half life period in several species, including humans, OTA can be detected for a prolonged time in blood plasma [28-30]. The elongated retention time in endotherm organisms might be partly due to a strong serum albumin binding of OTA, whereby the proportion of free-floating toxin is low. Another reason can be seen in alternative clearance pathways apart renal elimination, like the excretion via the biliary system and the enterohepatic recirculation of OTA-glucuronides $[28,30]$. Variation in sensitivity towards ochratoxin A between species and sexes might be due to differences considering transport mechanisms and cellular uptake within the renal tissue. Since ochratoxin presents a suitable substrate for various efflux transporters, in general, excretion via milk is possible [28,31]. Due to the heat-stability of OTA, raw as well as processed food commodities might be severely affected by ochratoxin contamination.

\subsubsection{Carry-Over of OTA in Livestock Species}

In pigs, OTA has been detected in kidney tissue and musculature, but in lower concentrations than in whole blood or blood plasma [30]. This might be of special concern for the processing of local specialities such as bloodpudding, lunchmeat and sausages, since many of these products include additives of pig-blood or -plasma. According to a study conducted by the EFSA in 2006, the mean OTA contamination level detected in porcine edible offals ranged between $0.17-0.20 \mu \mathrm{g} \cdot \mathrm{kg}^{-1}[28]$. The application of non-contaminated feed to pigs over a four-week period proved to be sufficient to clear away the major part of OTA residues from the animal organism. Using doses of OTA in assays (>1 mg $\mathrm{kg}^{-1}$ feed), carry-over was also observed in poultry. Although the half life time in poultry is short (4 hours), kidney lesions comparable to those seen in pigs have been found when using feed with $>200$ $\mu \mathrm{g}$ OTA $/ \mathrm{kg}$. Regarding these studies, poultry is thought to be a livestock species that is highly sensitive to ochratoxin A. Different statements can be found in the literature with regard to the transfer of OTA to milk and beef. Bacterial metabolism in the gastrointestinal tract, especially the rumen, yields the less toxic cleavage product ochratoxin $\alpha$. No measurable carry-over into beef could be detected [30], but this might only be true for fullgrown animals with a well-developed digestive system. In calves, carry-over ratios are similar to those seen in monogastric organisms. Feeding dairy cows a ration of grains contaminated with $25 \mathrm{mg}$ OTA $/ \mathrm{kg}$ feed resulted in a total uptake of $1.4 \mathrm{~g}$ over a period of one week. After seven days, a carry-over of $1.3 \mathrm{mg} \cdot \mathrm{kg}^{-1}$ milk was detected, presenting a transfer ratio of $0.7 \%$. The level of OTA in milk escaping the conversion to ochratoxin $\alpha$ is minute compared to the OTA contamination levels of grains seen during daily feeding practice. Even then, it is sufficient to pose a significant risk to consumers of large amounts, i.e. small children. A general survey of Italian infant formula producers revealed significant OTA contamination up to $689 \mathrm{ng} \cdot \mathrm{kg}^{-1}$, ready-to-use preparations being more affected than powdered samples [31].

\subsubsection{Limits Set for Ochratoxin in Feed Stuffs, Food, and Human Intake \\ Recommendation 2006/576/EC sets maximum levels of}


$0.05-0.25 \mu \mathrm{g} \cdot \mathrm{kg}^{-1}$ (88\% dry matter content assumed) for products intended for animal feeding [32].

Due to the high prevalence of Mycotoxic Porcine Nephropathy (MPE) in Scandinavian countries, a Danish regulation came into force declaring pork unfit for human consumption if OTA concentrations higher than 25 $\mu \mathrm{g} \cdot \mathrm{kg}^{-1}$ could be detected in the kidney tissue. Kidneys and liver were discarded if measured OTA concentrations ranged between 10 and $25 \mu \mathrm{g} \cdot \mathrm{kg}^{-1}$. Below a concentration of $10 \mu \mathrm{g} \cdot \mathrm{kg}^{-1}$ only the kidneys were rejected [30].

The average weekly human OTA intake was estimated to range between 21 and $60 \mathrm{ng} \cdot \mathrm{kg}^{-1} \mathrm{BW}$ [28]. The current Tolerable Weekly Intake (TWI) advised by the European Scientific Committee for Food (SCF) is $120 \mathrm{ng} \cdot \mathrm{kg}^{-1} \mathrm{BW}$, while the Joint WHO/FAO Expert Committee on Food Additives (JECFA) presented a PTWI of $100 \mathrm{ng} \cdot \mathrm{kg}^{-1}$.

\subsection{Fusarium Toxins-General Considerations}

Due to their high prevalence, ubiquitous distribution and multitude of harmful toxic products, fungi belonging to the genus Fusarium are considered to be of major importance with regard to human and livestock nutrition. Frequently, they infest growing crops on the field and can lead to primary intoxications of humans and livestock after intake. With respect to their carry-over potential, the role of these toxins is seen as subordinate, mainly because the farm animal will act as an effective filter organism. Since the 1970s an increase in the economic impact of Fusarium spp. can be observed. Since these moulds frequently infest maize and maize products, the problem of increasing contamination might partly arise from an on-going expansion of maize cultivation. Highly toxigenic strains of Fusarium spp. frequently occur in Europe. Fusarium roseum, Fusarium graminearum and Fusarium culmorum belong to the most common species. Cool humid periods and an early onset of frost followed by periods of bright sunshine can be seen as favourable climatic conditions for the infestation of crop with Fusarium spp. prior to harvest. The majority of the strains will produce at least two toxin types and co-occurrence of different Fusarium toxins frequently happens [33-35]. Fusarium toxins can be divided into three major groups.

\subsection{Zearalenone}

\subsubsection{Agricultural Commodities Affected}

Recently, the outstanding importance of zearalenone (ZEA) as a global contaminant of maize, wheat, barley, oats and sorghum was reviewed [36]. Apart from non-developed countries, serious contamination occurred in North America, where concentrations up to $2900 \mathrm{mg} \cdot \mathrm{kg}^{-1}$ grains were reported in 1999. Due to its fungal sources, ZEA is often combined with trichothecenes $[36,37]$, which underlines the importance to consider synergistic effects of mycotoxins.

\subsubsection{Adverse Health Effects in Humans and Animals} Zearalenone is constituted from phenole derivatives and its flexible molecular conformation mimics natural $17 \beta$ oestradiol actions after binding to oestrogen recaptors of target cells [38]. Hyperoestrogenic responses will result in permanent pathologic alterations of the reproductive tract, feminization in male organisms and disrupting reproductive processes in females. Differences in species' susceptibility are due to variations in number and affinity of oestrogen receptors. Pigs and sheep are considered to be high susceptible species. Generally, the exposure to zearalenone is more hazardous in growing, immature organisms than in adults [39]. The most fa- mous natural metabolites of ZEA are the stereoisomers $\alpha$-ZEA and $\beta$-ZEA.

\subsubsection{ZEA Biotransformation}

The formation of water soluble metabolites [40] or the conversion to zearalenone-glycosides induced by cooccurring Rhizopus fungi [41] frequently enhances the occurrence of masked mycotoxins. Degradation or inactivation of ZEA can mainly be achieved by application of chemical compounds like clay, activated carbon, montmorillonite or mannanoligosaccharides. It can also be mediated naturally by lactic acid bacteria, yeasts and other mould fungi [36]. Usually, a fast biotransformation within the animal as well as a speedy excretion via bile and urine prevent significant human dietary intake through meat and animal products.

\subsubsection{Carry-Over of ZEA to Various Species}

In pigs, no transfer of zearalenone and its major metabolites into serum was detected after a zearalenone administration of $56 \mu \mathrm{g} \cdot \mathrm{kg}^{-1}$ feed [42]. The liver showed a carry-over ratio of $0.9 \%$ whereas 4 -fold enrichment $(400 \%)$ in bile could be observed. Poultry seems to be very robust to ZEA although underlying principles have not been identified yet. One possible solution might be the naturally high level of oestrogen in poultry blood. Natural oestrogens are supposed to have a higher receptor affinity compared to Fusarium toxins. After an application of $0.04 \mathrm{mg} \mathrm{ZEA} / \mathrm{kg}$ feed in a 5-week feeding trial, plasma, liver and breast meat samples of male turkeys did not showed any detectable residual levels regarding zearalenone and its major metabolites [43]. The transfer rates to bile increased linearly dependent to the dietary ZEA concentration. No data of ZEA carry-over in commercially produced eggs was found [36]. In dairy species, transfer in milk occurs after ingestion of a very high dosage. Applying doses of $200 \mathrm{mg}$ ZEA/day via feed to a single dairy cow for seven days led to a carry-over of $0.7 \%$ into the milk [44]. In another study, doses of 545 
mg ZEA/day over a period of 21 days led to only low carry-over $(2.5 \mathrm{ng} \mathrm{ZEA} / \mathrm{ml})$ in a single cow. After oral administration of $1.8 \mathrm{mg}$ ZEA to a lactating sheep, transmission to milk was detectable after 24 hours, offering a concentration of $2 \mu \mathrm{g} \cdot \mathrm{kg}^{-1}$. The suckling lamb showed distinct symptoms of hyperoestrogenism after 10 days [45]. As to beef cattle, neither ZEA nor metabolites could be detected in muscles, offals and dorsal fat of a male bovine fed a daily diet containing $100 \mu \mathrm{g} \cdot \mathrm{kg}^{-1}$ feed [36].

\subsubsection{Limits Set for Zearalenone in Feed Stuffs and Human Intake}

Recommended limits in feeding-stuffs reach $0.1-0.5$ $\mathrm{mg} \cdot \mathrm{kg}^{-1}$ in nutritive additives and whole animal feed, whereas 2 - $3 \mathrm{mg} \cdot \mathrm{kg}^{-1}$ are considered tolerable in raw, unprocessed maize intended for feed production. The SCF evaluated an average daily intake ranging from 1.5 $\mu \mathrm{g}$ in Europeans to $3.5 \mu \mathrm{g}$ in Middle Eastern populations [39] The temporary Tolerable Daily Intake was calculated to be $0.2 \mu \mathrm{g} \cdot \mathrm{mg} \cdot \mathrm{kg}^{-1} \mathrm{BW}$.

\subsection{Deoxynivalenol (DON)}

\subsubsection{Producing Fungi and Commodities Affected}

Another category in Fusarium toxins is formed by the group of trichothecenes. Deoxynivalenol (DON) and T2-toxin are outstanding trichothecenes with respect to contamination of aliments and feedstuffs. DON can be produced by various strains of Fusarium, Trichothecium, Myrothecium, Stachybotris, Trichoderma, Cylindrocarpon and Verticimonosporium. Since the regional occurrence of different species is influenced by temperature, F. roseum, F. graminearum, F. culmorum and F. moniliforme are imminent within Europe with regard to toxin production. DON is considered to be the main fungal contaminant in wheat and maize grown in Canada, USA, England and Southern Africa.

\subsubsection{Adverse Health Effects in Humans and Animals}

Trichothecenes are highly reactive epoxide compounds known for having cytotoxic, immunotoxic and carcinogenic effects. Their inhibition of protein synthesis shows negative interference with cell division and synthesis of mRNA and DNA. Besides, the toxins enhance cellular apoptosis, mainly affecting lymphatic and haematopoietic tissue since those are directly dependent on a high rate of protein synthesis. Lymphocytes and epithelium cells, especially in the digestive tract, will react in the most susceptible way to toxic dosages. Adverse effects are more significant in growing, young organisms. Immunotoxic effects provided by trichothecenes are mirrored in severe leucopenia and lesions seen in lymphatic tissues. Consequently, affected organisms show decreasing resistance to challenges dependent on cellular immune-response like infections due to Mycobacteria and

\section{Salmonella.}

The most famous human disease caused by trichothecenes is Alimentary Toxic Aleukia (ATA). Human epidemics mostly occurred during World War II in Russia after consumption of grain overwintered on the fields. Furthermore, some Asian outbreaks were reported in India [46] and China [47] during the late 1980s. Usually, a co-occurrence of several trichothecenes [47] or an additional involvement of ZEA [37] can be observed during fusariotoxicosis. Symptoms of acute toxicity in humans might occur within an hour after uptake and usually include vomiting, abdominal pain, diarrhoea, burning sensation in the mouth, irritation of throat mucosa and bloody faeces. Continuing exposure might result in severe leucopenia and granulopenia, skin rashes and necrotic lesions.

\subsubsection{DON Biotransformation}

The epoxidal ring structure is responsible for toxicity and essential for biological activity. Biotransformation occurs via hydrolysis, hydroxylation, glucuronidation and deepoxidation, the latter being the most important elimination pathway.

Microbial degradation of DON within the rumen by de-epoxidation will result in a loss of toxicity for ruminants already at the stage of uptake. The de-epoxy-DON (DOM) concentration in the blood is significantly linearly correlated with the DON intake [48]. Hence, DOM can be used as a reliable in-vivo indicator matrix for DON. Naturally, DON is completely degraded in the rumen and will mainly be excreted by the renal route. The biliary system and the faeces are less important routes of clearance. DOM concentrations in bile increase in parallel to DON intake. Any DON residues are gone after 20 hours [49]. In ruminants, the DON metabolism might be altered by degenerative processes in the ruminal mucosa, as usually seen in subacute ruminal acidosis [48]. The transfer rate to milk is influenced by the total milk yield, which can be explained by a passive concentration dependent permeability gradient between blood and the alveolar cells of the udder. This permeability might also be severely influenced by local udder infections.

\subsubsection{Carry-Over of DON to Livestock Species}

In dairy ewes a carry-over to milk of less than $0.25 \%$ of the administered intravenous application rate $\left(4 \mathrm{mg} \cdot \mathrm{kg}^{-1}\right.$ BW) could be detected [50]. After a daily oral DON intake of $16.6-75.6 \mathrm{mg}$, the daily excretion via milk varied between 1 - $10 \mu \mathrm{g}$ (DON) and $14-104 \mu \mathrm{g}$ (DOM) in dairy cows. Carry-over ratio of DON in milk was in the range of $0.01 \%-0.02 \%$, while DOM showed a variation between $0.04 \%-0.24 \%$ [51]. No unmetabolised DON was detected in milk by Keeese et al. [48], whereas the 
DOM level ranged between LOD and $3.2 \mu \mathrm{g} \cdot \mathrm{kg}^{-1}$ milk, depending on the feeding period.

Having fed pigs both ad lib or with restrictive diets that contained up to $6.68 \mathrm{mg} \cdot \mathrm{kg}^{-1}$ over a period of twelve weeks, mean carry-over ratios subsuming DON and DOM were calculated for bile $(10 \%)$, kidneys $(1.5 \%)$, liver $(0.5 \%)$, serum $(0.23 \%)$, muscle $(0.16 \%)$ and fat $(0.02 \%)$ [42]. Recently, an even higher transfer of DON into tissue has been reported [52]. The major metabolite, DOM, could only be detected in bile and kidneys. Both authors observed high variation of DON carry-over into tissues due to individual endogenous effects. In poultry, the carry-over of DON into eggs had already been proven indirectly during the 1980s by using radioactive markers. In the first eggs laid a maximum of toxin concentration was detected followed by a decrease of toxin concentration in eggs laid later [53]. No detectable carry-over of DON and DOM was found in plasma (LOD $2 \mathrm{ng} \cdot \mathrm{ml}^{-1}$ ), liver and breast meat (LOD $4 \mathrm{ng} \cdot \mathrm{g}^{-1}$ ) of turkeys after a long-time feeding experiment including $5.4 \mathrm{mg} \mathrm{DON} / \mathrm{kg}$ feed [43]. Confirming previous reports, the concentration in bile was higher, showing high interindividual variance $\left(13-23 \mathrm{ng} \cdot \mathrm{ml}^{-1}\right)$.

No human diseases due to carry-over have been reported yet, since the animal organism probably acts as an efficacious filter unit. Besides, farm animals will usually refuse feeding stuffs that are highly contaminated with DON due to its neurotoxic effect, caused by an interaction with serotonin metabolism. Hence, DON is primarily of economic importance due to its severe depression of animal productivity.

\subsubsection{Limits Set for DON in Feed Stuffs and Human Intake}

The maximum level in feeding-stuffs within the EU (Recommendation 2006/576/EC) is set for $8-12 \mathrm{mg} \cdot \mathrm{kg}^{-1}$ in unprocessed cereal products and $5 \mathrm{mg} \cdot \mathrm{kg}^{-1}$ in total feed and feed additives [32]. Limits for pigs are set lower, ranging between 0.9 and $2.0 \mathrm{mg} \cdot \mathrm{kg}^{-1}$ with respect to different age groups. In 2002, the TDI proposed by the SCF was $1 \mu \mathrm{g} \cdot \mathrm{kg}^{-1}$ BW/day in DON whereas a t-TDI of 0.7 $\mu \mathrm{g} \cdot \mathrm{kg}^{-1} \mathrm{BW} /$ day was advised for Nivalenol $[54,55]$.

\subsection{Fumonisin B}

\subsubsection{Producing-Fungi and Commodities Affected}

Fumonisins are classified in the third group of Fusarium toxins. They are mainly produced by Fusarium moniliforme which can be frequently found on maize. In healthy maize kernels, fumonisin concentrations up to 10 $\mathrm{mg} \cdot \mathrm{kg}^{-1}$ may occur, while mouldy ones may have 60 $140 \mathrm{mg}$ fumonisin $/ \mathrm{kg}$. Cereals including sorghum as well as rice, beer, asparagus, dates and mung beans are food commodities also high-at risk.

\subsubsection{Fumonisin Biotransformation and Adverse Health Effects in Humans and Animals}

While fumonisin B1, B2 and B3 are considered the most hazardous agents due to their toxicity, B1 is the most important one. The key structure for biological activity and toxicity, presented by the free amino group, is blocked by the formation of Schiff bases. The presence of reducing oligosaccharides (glucose or fructose) in the diet therefore results in a loss of toxicity.

Fumonisin B proved to be hepatotoxic in all species examined while nephrotoxicity only appeared to affect several species including rodents. Hepatic involvement contains toxic hepatitis and cholangiofibrosis. Since they elicit oxidative cellular stress, fumonisins are believed to have a tumour initiating and promoting activity finally resulting in cholangiocarcinoma. Despite they do not offer any direct genotoxic and mutagenous effect, fumonisins can be considered to be cytotoxic. This effect can partly be explained by an interaction of fumonisin with the lipid metabolism. Toxic effects on reproduction are linked to erroneous development of the neural tube and will also only occur during exposure to doses adverse to the mother organism.

Few data are available for acute toxicity in humans which is usually linked to self-limiting symptoms of gut irritation and diarrhoea [56]. In livestock, swine and horses belong to the species that are severely affected by fumonisin intoxication. In pigs, a myocardial affection of the left ventricle will result in severe lung oedema and hydrothorax. Fumonisin intoxication in horses elicits a special syndrome called equine leucoencephalomalacia (ELEM). It is characterized by focal malacia, cerebral oedema and a liquefaction of the cerebral white matter. Symptoms might appear after a couple of hours.

\subsubsection{Carry-Over of Fumonisins to Swine}

Fumonisin carry-over in sow milk and pork meat might only happen after a high long-term exposure. Pigs fed a fumonisin-enriched diet containing $2-3 \mathrm{mg} \cdot \mathrm{kg}^{-1}$ did not have any accumulation in milk and muscles, whereas liver and kidney turned out to be contaminated. The missing transfer to milk was confirmed in sows after the intake of $100 \mathrm{mg}$ fumonisin $\mathrm{B} 1 / \mathrm{kg}$ feedstuff during 14 days [57].

\subsubsection{Limits Set for Fumonisins in Feed Stuffs and Human Intake}

Since B2 and B3 have similar toxic effects as fumonisin $\mathrm{B} 1$, the three of them are subsumed using recommended maximum levels in feedstuffs ranging from $5 \mathrm{mg} \cdot \mathrm{kg}^{-1}$ (horses, pigs) to $50 \mathrm{mg} \cdot \mathrm{kg}^{-1}$ (adult ruminants). Estimates concerning the level of human exposure vary between 
$0.1 \mu \mathrm{g}$ and $14 \mu \mathrm{g}$. Threshold limits concerning human exposure were published by the JECFA in 2001, advising a Provisional Maximum Tolerable Daily Intake (PMTDI) of $2 \mu \mathrm{g} \cdot \mathrm{kg}^{-1} \mathrm{BW}$.

\subsection{Patulin}

\subsubsection{Producing Fungi and Commodities Affected}

Patulin is one of the various toxins produced by several Penicillium and Aspergillus fungi. It primarily appears in damaged fruit, vegetables and subsequently in fruit juice. Occasionally, it can be seen as co-contaminant in agricultural commodities or in by-products intended for animal feeding $[58,59]$. Patulin usually shows high instability in foods rich in sulfhydryl compounds, like fruits, grains and meat [60].

\subsubsection{Adverse Health Effects in Humans and Animals} Various cytotoxic effects are offered by patulin, causing damage to the immune system, the pancreas, the liver and the gastrointestinal tract. In cattle, acute intoxication is characterized by gut haemorrhages and neurotoxicity, resulting in tremors, paralysis and death [59]. The antibiotic properties of patulin can show side effects on the gut flora, especially in ruminants [7].

\subsubsection{Patulin Biotransformation and Carry-Over}

There is only little information available regarding biotransformation and carry-over. Patulin is metabolised in the liver. Elimination pathways include faeces and urine. The major part of the toxin is cleared within the first $24 \mathrm{~h}$. A carry-over of $2 \%-3 \%$ in soft tissue and blood in general is possible.

\subsubsection{Limits Set for Patulin in Food and Human Intake} The main reason for the importance of patulin for humans is largely due to baby- and infant-nutrition. Youngsters are treated as a highly vulnerable group having an extended risk of exposure [26]. Maximum limit for food set within the EU incorporates $25-50 \mu \mathrm{g} \cdot \mathrm{kg}^{-1}$ for fruit juices and compote; whereas a stricter limit $\left(10 \mu \mathrm{g} \cdot \mathrm{kg}^{-1}\right)$ is declared for products intended for infant nutrition. The PMTDI in humans was estimated to be $0.4 \mu \mathrm{g} \cdot \mathrm{kg}^{-1} \mathrm{BW}$ by the JECFA.

\section{Further Mycotoxins Relevant to Human Health and Carry-Over}

\subsection{T-2 Toxin}

Both T-2 toxin and its co-occurring major metabolite HT-2 are trichothecenes. Even if T-2 and HT-2 show high variation in feedstuffs and food with regard to frequency and concentration $[33,61,62]$, they pose a severe health risk to livestock and humans because of their high toxicity.

3.1.1. Adverse Health Effects in Humans and Animals Besides common adverse health effects usually associated with trichothecenes, T-2 adds haematotoxicity, reflected by extensive haemorrhagies seen in mucosal tissues and organs. Since T-2 can frequently be detected in matrices contaminated by further mycotoxins, it obviously has a high impact on diseases with a multi-toxic origin [46], providing synergistic or additive toxic effects [63].

\subsubsection{T-2 Biotransformation and Carry-Over}

Fast metabolism and biotransformation of T-2 are thought to prevent accumulation in animal tissue. Consequently, $\mathrm{T}-2$ does not have any relevance regarding carry-over in general [60]. Even then, transfer to milk is possible, reaching a level of $0.5 \%-2.0 \%$ [7].

\subsubsection{Limits Set for T2/HT2 in Feed Stuffs, Food, and Human Intake}

Actually, there is still a lack of statutorily fixed national or European maximum limits, although the JECFA defined the combined Provisional Maximum Tolerable Daily Intake with $0.06 \mu \mathrm{g} \cdot \mathrm{kg}^{-1}$ for T-2 and HT-2. This value was confirmed by the EFSA in 2001 and is referred to as temporary Total Daily Intake (t-TDI).

\subsection{Ergot Alkaloids}

\subsubsection{Fungal Sources and Commodities Affected}

By definition, ergot alkaloids do not belong to the mycotoxins, but they pose a fungal product group hazardous to human health. These alkaloids are produced within the sclerotia of various endophytes, especially Claviceps purpurea and Claviceps africana. Ergot is a common parasitic fungus in rye, but might also infest triticale, wheat, spelt, barley, oat and grass. The increasing prevalence of ergot during the last twenty years mainly results from the expanded cultivation of rye-hybrid species and triticale, but might be influenced by further factors like an increase of unprocessed trimmings. Ergot produces a variety of alkaloids. The composition and toxin concentration is highly variable within-sclerotium, within-head, head-to-head and on a field-to-field basis.

3.2.2. Adverse Health Effects in Humans and Animals Ergometrine, ergotamine, ergosine, ergocritine, ergocryptine, ergocornine and their inine metabolites are some of the most prominent alkaloids. Ergot alkaloids offer dopaminergic, serotinergic and adrenergic effects that will result in general vasoconstriction and in severe interference of the neurotransmitter response. The spectrum of clinical symptoms can differ dependent on the predominating toxin, but may include reduced feed intake, convulsions, hallucinations, agalactiae, abortions, 
stillbirth, lameness and severe necrosis, usually seen in the extremities.

The so-called ergotism has been known in Europe for many centuries and has been referred to as "St. Anthony' s fire" in humans. Ergotism can be seen in a gangrenous or in a convulsive disease course. The last severe outbreak of gangrenous ergotism in humans was seen in Ethiopia in 2002 [64].

\subsubsection{Biotransformation of Ergot Alkaloids}

Alkaloids will be absorbed in the intestine after oral ingestion, bioavailability and speed of absorption depending directly on their chemical structure. Some derivatives are able to pass the blood-brain barrier or the placenta barrier. After a first-pass metabolism in the liver, the final excretion is biphasic due to enterohepatic recirculation. There is only scarce specific data available for the kinetics of ergot alkaloids in food producing animals: In ruminants, ergot alkaloids will partly be absorbed during the ruminal passage $[7,65]$, the proportion directly influenced by the passage rate of ingesta. The climax level seen in blood samples is reached within two hours after intake.

\subsubsection{Carry-Over of Ergot Alkaloids to Livestock Species}

While in a prior study no alkaloid residues in porcine samples were reported after administering ergot to pigs [66], information with regard to quantity of total exposure and subsets of alkaloids was missing. This result was recently confirmed when feeding a maximum of $4.66 \mathrm{mg}$ total alkaloids (10 g ergot) to growing-finishing pigs [67].

In poultry, transfer of ergot alkaloids to liver and skeleton muscles could only be observed in a long-term feeding trial (51 days) [68]. $800 \mathrm{mg}$ ergotamine $/ \mathrm{kg} /$ day resulted in a residual level below $10 \mu \mathrm{g} \cdot \mathrm{kg}^{-1} \mathrm{BW}$. This study took into account only the compound ergotamine.

There is little information available with regard to carry-over in beef. A long-term feeding trial (230 days) in bulls fed diets up to $421 \mu \mathrm{g}$ total alkaloids $/ \mathrm{kg} \mathrm{DM}$ $(2.25 \mu \mathrm{g} \cdot \mathrm{ergot} / \mathrm{kg})$ did not gave any hints confirming carry-over of ergot alkaloids into tissues [69]. Carry-over of ergot alkaloids into milk has been inconsistently described. On the one hand, an old study revealed detectable milk concentrations of $86 \mu \mathrm{g} \cdot \mathrm{L}^{-1}$ after feeding $50 \mathrm{~g}$ ergot sclerotia per animal to dairy cows [70]. On the other hand, after administering silage contaminated with $0.1 \%$ ergot $(0.132 \%$ total alkaloids in the ergot portion), all milk samples of cows showing severe clinical disease were negative for ergot alkaloids [71]. Wolf et al. (1995) could not detect any residues in milk after administration of large amounts of feed contaminated with ergot alkaloids at a practically relevant level resulting in a daily intake of $1835 \mu \mathrm{g} / \mathrm{animal}$ (i.e. $3 \mu \mathrm{g} \cdot \mathrm{kg}^{-1} \mathrm{BW}$ ) [72]. This was confirmed in a four weeks feeding trial. Feeding diets with $504-620 \mu \mathrm{g} \cdot \mathrm{kg}^{-1}$ DM to cows resulted in an intake of $4.1-16.3 \mu \mathrm{g} \cdot \operatorname{ergot} / \mathrm{kg}$ BW. In milk or blood, no carry-over was detectable [65].

\subsubsection{Limits Set for Ergot Alkaloids in Feed Stuffs, Food, and Human Intake}

The level of contamination in feed and food commodities is usually expressed as percentage of sclerotia present within agricultural commodities. Regulation (EC) 824/2000 claims that the consumption grain must not be contaminated with more than $0.05 \%$ ergot $(500 \mathrm{mg}$ sclerotia $/ \mathrm{kg}$ grain) [73]. Presuming a mean total alkaloid proportion of $0.2 \%$ in ergot, a subsequent calculated limit of 1 $\mathrm{mg} \cdot \mathrm{kg}^{-1}$ cereals is permitted at present; though some authors advise that maximum limits for ergot in rye and wheat should not exceed $100 \mu \mathrm{g} \cdot \mathrm{kg}^{-1}$ [74].

Within the EU, a maximum limit of $0.1 \%$ is declared for rye ergot in all feedstuffs containing non-ground cereals (Council directive 1999/29/EC) [75], but no limits are given for individual alkaloids. Comparable to the EU, Australia limits the proportion of ergot to $0.05 \%$ in food cereals. In North America, the maximum permissive level in feed grain actually is $300 \mathrm{mg} \cdot \mathrm{ergot} / \mathrm{kg}$.

Today, judgement of contamination by the percentage of sclerotia present in feed grain is considered as inaccurate since there are high variations regarding weight, size and composition within the sclerotia. Adverse health effects may occur in farm animals fed with feed compliant though close to the limit level [74]. The process of estimating the level of total alkaloid contamination in commodities by chemical analysis of single ergot alkaloids is hampered by the fact that there is a high variety in toxic amounts and composition apart from co-occurrence of toxins. Besides, there is not any alkaloid that can be called an appropriate indicator toxin and neither the total amount nor a single alkaloid can be used for reliable estimation of adverse health effects.

Some nations have established statutory limits for total alkaloids in feedstuffs. In Canada, fodder intended for pigs has a limit of $6000 \mu \mathrm{g}$ alkaloids $/ \mathrm{kg}$ feed, while there is a stricter limit for fodder intended for dairy cows, sheep and horses $\left(3000 \mu \mathrm{g} \cdot \mathrm{kg}^{-1}\right)$ and an even higher limit in chicks $\left(9000 \mu \mathrm{g}^{\mathrm{kg}} \mathrm{kg}^{-1}\right.$ feed).

\subsection{Citrinin}

3.3.1. Fungal Source Species and Commodities Affected Citrinin is declared as a co-contaminant to various mycotoxins and thus is of importance i.e. for multi-toxin analysis. Since this mycotoxin is produced by several species belonging to Penicillium, Aspergillus and Monascus fungi, contamination usually occurs during storage. $\mathrm{Ci}$ trinin exploits damaged fruit and vegetables and might be 
isolated out of juice and wine. It was found contaminating food cereals, but can also be present in grains and silage intended for animal feeding. Citrinin can be detected in vegetarian sausages and Asian delicacies dyed using fermented red mould rice. It was occasionally present in spoiled smoked ham or mouldy cheese, too [76].

3.3.2. Adverse Health Effects in Humans and Animals Citrinin proved to be highly nephrotoxic, showing synergistic effects with OTA to which it is a concomitant cocontaminant $[60,77]$. Involvement of citrinin in Mycotoxic Porcine Nephropathy and Balcan Endemic Nephropathy is generally discussed [77]. Citrinin is also considered to be cytotoxic, teratogenic, embryogenotoxic and genotoxic. Due to its inhibition of protein synthesis, citrinin might offer synergism to further mycotoxins, especially to the group of trichothecenes. Since the cancerogenity in humans is not clear, citrinin was classified in group 3 by the IARC. In the past, a reliable detection of citrinin was impossible since the toxin is unstable in aqueous solutions and usually shows degradation in the food matrix or during sample preparation. Common methods of analysis are frequently impaired by technical problems due to its chemical structure [60].

\subsubsection{Citrinin Biotransformation and Carry-Over}

After a fast metabolism, citrinin will be excreted via the renal way. There is only scarce information available regarding carry-over. In poultry, Abdelhamid \& Dorra (1990) found significant changes in meat yield and quality as well as in egg quality after administration of 100 $\mu \mathrm{g} \cdot \mathrm{kg}^{-1}$ aflatoxins, citrinin, or patulin for six weeks [78]. Citrinin residues reached levels of $10 \mu \mathrm{g} \cdot \mathrm{kg}^{-1}$ in fresh muscle and yolk whereas egg white showed a lower (6 $\mu \mathrm{g} \cdot \mathrm{kg}^{-1}$ ) transfer ratio.

Since citrinin is occurring discontinuously and had been not easy to detect for decades, only few empiric data is available with regard to hazard assessment and dietary exposure in humans.

\section{Carry-Over Research}

\subsection{Current Problems Linked to Mycotoxin Carry-Over Research}

For the evaluation of the results presented in literature, it is necessary to take a closer look at study designing. Factors to be considered, as far as they are declared, not only include the amount of mycotoxins applied, but also the frequency of doses as well as the way of application. Using artificially or naturally contaminated fodder [79] might prove as important as the ration composition during the feeding trial, the qualitative state of all feed ingredients (background contamination) and the cooccurrence of various mycotoxins or several metabolites. Carry-over ratios might be influenced by species, breed, sex, production or age groups as well as by the production level and general health status. Periods of toxin withdrawal certainly influence the accumulation of mycotoxins in tissues. The scale of the trial with regard to the number of animals included and the period of exposure are as important as the moment or the intervals of measurements. Precise values of carry-over ratios sometimes differ largely between various studies. That can partly be explained by varying levels of detection (LODs) linked to different substances and by the method chosen for analysis.

The way how the results were calculated from measured raw data has a further effect on the outcome of a study. Thus, non-detectable (n.d.) measurement data are often included by application of the "n.d./2" method. This formula equals all measurements with nondetectable values to half the detection limit of the application chosen. This may lead to misinterpretation or overestimation, especially when there are only high measurement limits.

Hence, it should not be concluded from negative results that the mycotoxic target substance is not present in the sample. False negative results arise from a high LOD of the chosen method or from the instability of the mycotoxic compound during analysis [76]. In addition, the occurrence of unknown [80] or unattended [81,7] metabolites not easily detectable by routine analysis has to be considered. Furthermore, the homogeneity of the sample preparation is of essential importance since the target substance might occur in clusters [48].

Masked mycotoxins fixed in special chemical compounds and therefore difficult to detect are a special problem when using naturally contaminated feed ingredients within a ration. First of all, the amount of mycotoxin application determined within the trial is incorrect. Secondly, they might contribute to background contamination. For example, the proportion of DON-3- $\beta$-Dglycopyranoside not detectable by common HPLC technique revealed to be up to $12 \%$ in naturally contaminated wheat and maize samples [48]. Naturally contaminated diets might include a variety of metabolites besides the parent toxin making the evaluation of carry-over more difficult. This is of special interest in ruminal metabolism, where non-extractable toxins might be liberated and converted into high-absorbable compounds [7]. This generates uncertainties with regard to precise correlation of in-feed mycotoxin levels against internal effective doses.

\subsection{Carry-Over Risk Assessment}

By definition, carry-over can only include foodstuffs of animal origin. Transfer ratios published usually show some variation, but in general values below $1 \%$ are found 
for skeletal musculature. Higher ratios of mycotoxins compared to meat have been determined especially in blood serum and in fat tissue. Based on their function in detoxification, higher carry-over ratios can generally be seen in liver and kidney tissue when compared to other organs or muscle tissue. Taken up by the host organism, these toxins initially reach the blood stream resulting in measured maximum concentrations. Thus carry-over ratios do not only vary with regard to toxin type and animal host species but also within the range of tissue samples drawn from a single host organism.

Within the EU especially aflatoxins and OTA are of practical interest in view of carry-over from feed to food. Due to their monogastric digestive system pigs are prone to be one of the most sensitive livestock species with regard to adverse health effects and carry-over. Ruminants revealed to be of minor importance due to their endogenous ruminal detoxification with exception of aflatoxin $\mathrm{M}$, which can be frequently found in milk. This impact of mycotoxins in milk is reflected in legislation by additional limits for baby and infant food. Nevertheless, recent studies revealed the transfer of the intercomversion metabolite aflatoxicol into milk [81]. Aflatoxicol has to be considered as harmful as its parent toxin B1 and poses even a higher health risk than AFM1. Since it is not detectable via fluorescence, its occurrence is not covered by actual control and surveillance programmes. Even if the major part of OTA is transformed to the less potent ochratoxin $\alpha$ during ruminal metabolism, there are traces of OTA in milk escaping biotransformation. Within the EU, there is not any regulation that declares OTA contents in milk. This is a problem in children that are believed to exceed the advised TDI of $5 \mathrm{ng} / \mathrm{kg}$ $\mathrm{BW} /$ day by main consumption of cow milk contaminated with common OTA levels. Recently, Meucci et al. (2010) reported significant OTA contamination of pre-term ready-to-use infant formula sufficient to cause an elevated intake of OTA [31]. Since modulations in immune response proved to be elicited by ochratoxin concentrations far below the doses that are considered necessary to cause visible adverse effects, a main focus in amending future food safety regulation should include extended OTA and OTB surveillance.

Data available for zearalenone, DON, T-2 and ergot is contradictory. Despite in most cases carry-over might be neglected, a significant variation due to unfavourable conditions is conceivable. These might not only include the occurrence of mycotoxins in agricultural commodeties at an unforeseen high level, but also adverse ruminal and udder health condition common in high-performing dairy cattle. This should not only be considered with regard to total exposure, but might also be of special inter- est in population segments already at higher risk (infants, children, pregnant women, stilling mothers, humans ergotised for therapeutic treatment). Especially for ergot alkaloids, fixing of a legal maximum level has proven to be difficult in the past. This must be traced back to a discontinuous pattern of distribution, a varying concomitant composition and differing biological activities of ergot alkaloids. The simple definition of a total alkaloid permissive level therefore might be as inappropriate as choosing one alkaloid as indicator metabolite.

Even mycotoxins that, as far as known, are not directly affected by carry-over, might catch attention in livestock nutrition since they are attested to have depressing effects on animal health and performance. Mycotoxins do not only show influence on quantitative animal performance but can also severely affect product quality, especially those of eggs and meat. Moreover, antimicrobial effects of mycotoxins pose not only a risk to the ruminal flora but can also impair the fermentation of dairy products, posing the latter at a higher risk of spoilage.

Various mycotoxins, like the trichothecenes and ochratoxins, are noted for their modulation of immune response. In animals as well as in humans this might be mirrored by an increased prevalence of infectious diseases and an acceleration of minor infections. Decrease in immune response not only interferes with various vaccination programmes but also poses a risk to the success of repressing and removing microorganisms like Listeria, Salmonella and Mycobacteria from the food chain.

In animals continuously fed on diets containing significant mycotoxin levels there is a risk of toxin accumulation beyond compliance even if the feed used does not exceed the actual recommendations [21,82]. Consequently, a revision of these recommendations should be advised. Another reason is that feed recommendations were mainly set to avoid adverse effects with high economic impact on animal health and performance, but not with regard to carry-over. For example, only cows with a total daily uptake of less than $40 \mu \mathrm{g}$ AFB1 will produce milk compliant with the AFM level permitted within the EC (50 ng $\left.\cdot \mathrm{kg}^{-1}\right)$ [83].

A further problem linked to carry-over can be seen in the enrichment of several mycotoxins due to food processing, as it can be seen for milk powder (AFM, OTA) and in curd, whey and cheese (AFM) [6,18,21,31]. The latter problem is even aggravated by a lack of harmonized international regulations ensuring a minimal presence of AFM in dairy products like cheese. Even then, commonly applied maximum levels usually are out of range for developing nations suffering from high levels of contamination in their primary products due to geographic, climatic and socioeconomic conditions. Even if 
single published examples show that there are still breaches in the European system ensuring food quality [31,84], the implementation of food quality systems, monitoring and surveillance, as for example the Rapid Alert System for Food and Feed (RASFF), have resulted in a general decrease of contamination seen in products placed on the European market.

\subsection{New Trends in Carry-Over Research}

Carry-over research has already experienced a change in focus. Studies reporting carry-over effects achievable under extreme doses have turned out to be valuable for initial screening. Current research focuses on mycotoxin concentrations which are practically relevant, mainly by using diets that are naturally contaminated. Despite the need of further expanding carry-over research by using common exposure levels, climatic changes and rising extreme weather conditions must be kept in mind, too. Both unexpected mycotoxins and unattended levels of contaminations are more likely to be observed in the future. Since carry-over is highly dependent on the animal health status, animals with disease alterations frequently seen in daily routine, like hepatic damage, mastitis and ruminal acidosis, have to be taken into account to in carry-over research, as well.

With regard to transfer into products of animal origin, only the basics of mycotoxin activity have been elucidated. In many cases, standardised parameters for the calculation of carry-over still not exist [82] and trials usually are not comparable due to different study designs. In addition, synergistic properties have rarely been a topic of research so far. Since they are of high practical relevance, it is recommendable to put the focus here in future years. At present, research is focused on a minority of livestock species. Literature concerning carry-over into less important and rare livestock species can hardly be found. In order to do justice to the fact that mycotoxins can induce species-specific highly differing effects, research should be diversified. Especially with regard to the carry-over research in dairying species, more attention should be paid to small ruminants and exotic species since there is an expanding demand on those dairy products.

Until now synergistic additive, cumulative or antagonistic effects between mycotoxins as well as possible buffer effects of other feed components have rarely been investigated systematically. The common detection of co-occurring mycotoxins within a single agricultural commodity [85] emphasizes the importance of strengthening research regarding combined mycotoxin effects. This is of special interest in ruminants, where little is known concerning the ruminal stability, oral availability, and mycotoxin interaction at ruminal level. Moreover, recent developments in animal nutrition like the use of protected concentrated proteins designed to bypass the rumen have to be taken into account in carry-over research. Recently, first steps were taken to develop commercial tests for multi-analysis $[35,85,86]$.

New topics with regard to carry-over could be the revision of aflatoxin surveillance, being expanded to include precursor compounds like sterigmacystein as well as minor metabolites, like aflatoxicol. Establishing new methods, for example the in vitro use of active transport mechanisms like ABCG2 and BCRP, might be worthwhile for a better estimation of the galactogenic excretion of mycotoxins like aflatoxins and OTA. Little is known about the importance of carry-over regarding mycotoxins like citrinin and patulin whose major impact on human health was believed to be the consumption of directly contaminated plant-derived products. Especially in citrinin, reliable detection technology was developed only recently, so wide-scaled research has not been possible so far.

\section{Conclusions}

Importance and relevance of the subject presented in our study can be demonstrated by an estimate of the United States Department of Agriculture (USDA) saying that $25 \%$ of all food and feed worldwide is contaminated with mycotoxins. For food safety this is a serious problem since the ubiquitous presence of mycotoxins in feed and food can induce various toxic effects such as pathological conditions and emergence of cancer. A universally valid evaluation of victual contamination with mycotoxins is difficult since their presence is discontinuous and hence a constant exposure of consumers can not be assessed. We concluded the necessity to emphasize studies dealing with toxin-interactions at the level of absorption and bioavailability. With regard to synergism effects of co-occurring toxins, monitoring and surveillance should be expanded to mycotoxins and metabolites that are thought to be neglectable with regard to transfer into tissues. This underlines the importance of an efficient quality management on behalf of the EU to ensure a maximum of protection for the consumers.

\section{Acknowledgements}

Special thanks to Jessica Olbrich for improving the English style.

\section{REFERENCES}

[1] L. Lewis, M. Onsongo, H. Njapau, H. Schurz-Rogers, G. Luber, S. Kieszak, J. Nyamongo, L. Backer, A. M. Dahiye, A. Misore, K. DeCock, C. Rubin and the Kenya Aflatoxicosis Investigation Group, "Aflatoxin Contamination of Com- 
mercial Maize Products During an Outbreak of Acute Aflatoxicosis in Eastern and Central Kenya," Environmental Health Perspectives, Vol. 113, No. 12, 2005, pp. 1763-1767. doi:0.1289/ehp. 7998

[2] R. F. Hall, L. R. Harrison and B. M. Colvin, "Aflatoxicosis in Cattle Pastured in a Field of Sweet Corn," Journal of the American Veterinary Medical Association, Vol. 194, No. 7, 1989, p. 938.

[3] U.S. Food and Drug Administration Center for Food Safety and Applied Nutrition, "Bad Bug Book: Foodborne Pathogenic Microorganisms and Natural Toxins Handbook," International Medical Publishing, Inc., Springfield, 2003.

[4] K. Sugiyama, H. Hiraoka and Y. Sugita-Konishi, "Aflatoxin M1 Contamination in Raw Bulk Milk and the Presence of Aflatoxin B1 in Corn Supplied to Dairy Cattle in Japan," Shokuhin Eiseigaku Zasshi, Vol. 49, No. 5, 2008, pp. 352-355. doi:0.3358/shokueishi.49.352

[5] B. de Meulenaer, "Chemical Hazards," In: P. A. Luning, F. Devlieghere and R. Verhé, Eds., Safety in the Agri-Food Chain, Wageningen Academic Publishers, Wageningen, 2008, pp. 145-208.

[6] G. Battacone, A. Nudda, M. Palomba, M. Pascale, P. Nicolussi and G. Pulina, "Transfer of Aflatoxin B1 from Feed to Milk and From Milk to Curd and Whey in Dairy Sheep Fed Artificially Contaminated Concentrates," Journal of Dairy Science, Vol. 88, No. 9, 2005, pp. 3063-3069. doi:0.3168/jds.S0022-0302(05)72987-8

[7] J. Fink-Gremmels, "Mycotoxins in Cattle Feeds and CarryOver to Dairy Milk: A Review," Food Additives and Contaminants, Vol. 25, No. 2, 2008, pp. 172-180. doi:0.1080/02652030701823142

[8] W. F. Busby and G. W. Wogan, "Aflatoxins," In: C. E. Searle, Ed., Chemical Carcinogens, Vol. 2, American Chemical Society, Washington D.C., 1984.

[9] R. A. Coulombe Jr., "Biological Action of Mycotoxins," Journal of Dairy Science, Vol. 76, No. 3, 1993, pp. 880-891.

[10] A. D. Liggett, B. M. Colvin, R. W. Beaver and D. M. Wilson, "Canine Aflatoxicosis: A Continuing Problem," Veterinary and Human Toxicology, Vol. 28, No. 5, 1986, pp. 428-430.

[11] R. W. Beaver, D. M. Wilson, M. A. James, K. D. Haydon, B. M. Colvin, L. T. Sangster, A. H. Pikul and J. D. Groopman, "Distribution of Aflatoxins in Tissues of Growing Pigs Fed an Aflatoxin-Contaminated diet amended with a High-Affinity Aluminosilicate Sorbent," Veterinary and Human Toxicology, Vol. 32, No. 1, 1990, pp. 16-18.

[12] C. A. Oliveira, E. Kobashigawa, T. A. Reis, L. Mestieri, R. Albuquerque and B. Correa, "Aflatoxin B1 Residues in Eggs of Laying Hens Fed a Diet Containing Different Levels of the Mycotoxin," Food Additives and Contaminants, Vol. 17, No. 6, 2000, pp. 459-462. doi:0.1080/02652030050034037

[13] A. Zaghini, G. Martelli, P. Roncanda, M. Simioli and L. Rizzi, "Mannanoligosaccharides and Aflatoxin B1 in Feed for Laying Hens: Effects on Egg Quality, Aflatoxins
B1 and M1 Residues in Eggs, and Aflatoxin B1 Levels in Liver," Poultry Science, Vol. 84, No. 6, 2005, pp. 825832.

[14] A. Bintvihok, S. Thiengnin, K. Doi and S. Kumagai, "Residues of Aflatoxins in the Liver, Muscle and Eggs of Domestic Fowls," The Journal of Veterinary Medical Science, Vol. 64, No. 11, 2002, pp. 1037-1039. doi:0.1292/jvms.64.1037

[15] M. Denli, J. C. Blandon, M. E. Guynot, S. Salado and J. F. Perez, "Effects of Dietary AflaDetox on Performance, Serum Biochemistry, Histopathological Changes, and AflaToxin Residues in Broilers Exposed to Aflatoxin B(1)," Poultry Science, Vol. 88, No. 7, pp. 1444-1451. doi:0.3382/ps.2008-00341

[16] S. A. Aly and W. Anwer, "Effect of Naturally Contaminated Feed with Aflatoxins on Performance of Laying Hens and the Carryover of Aflatoxin B1 Residues in Table Eggs," Pakistan Journal of Nutrition, Vol. 8, No. 2, 2009, pp. 181-186. doi:0.3923/pjn.2009.181.186

[17] S. Ruangwises and N. Ruangwises, "Occurrence of Aflatoxin M1 in Pasteurized Milk of the School Milk Project in Thailand," Journal of Food Protection, Vol. 72, No. 8, 2009, pp. 1761-1763.

[18] M. T. Montagna, C. Napoli, O. De Giglio, R. Iatta and G. Barbuti, "Occurrence of Aflatoxin M1 in Dairy Products in Southern Italy," International Journal of Molecular Sciences, Vol. 9, No. 12, 2008, pp. 2614-2621. doi:0.3390/ijms9122614

[19] M. M. Motawee, J. Bauer and D. J. McMahon, "Survey of Aflatoxin M(1) in Cow, Goat, Buffalo and Camel Milks in Ismailia-Egypt," Bulletin of Environmental Contamination and Toxicology, Vol. 83, No. 5, 2009, pp. 766-769. doi:0.1007/s00128-009-9840-3

[20] E. Rahimi, M. Bonyadian, M. Rafei and H. R. Kazemeini, "Occurrence of aflatoxin M1 in Raw Milk of Five Dairy Species in Ahvaz, Iran," Food and Chemical Toxicology, Vol. 48, No. 1, 2010, pp. 129-131. doi:0.1016/j.fct.2009.09.028

[21] G. Battacone, A. Nudda, A. Cannas, A. C. Borlino, G. Bomboi and G. Pulina, "Excretion of Aflatoxin M1 in Milk of Dairy Ewes Treated with Different Doses of Aflatoxin B1," Journal of Dairy Science, Vol. 86, No. 8, 2003, pp. 2667-2675. doi:0.3168/jds.S0022-0302(03)73862-4

[22] G. Battacone, A. Nudda, M. Palomba, A. Mazzette and G. Pulina, "The Transfer of Aflatoxin M1 in Milk of Ewes Fed Diet Naturally Contaminated by Aflatoxins and Effect of Inclusion of Dried Yeast Culture in the Diet," Journal of Dairy Science, Vol. 92, No. 10, 2009, pp. 4997-5004. doi:0.3168/jds.2008-1684

[23] "Opinion of the Scientific Panel on Contaminants in Food Chain on a Request From the Commission Related to Aflatoxin B1 as Undesirable Substance in Animal Feed. Request № EFSA-Q-2003-035," The EFSA Journal, No. 39, 2004, pp. 1-27.

[24] Arbeitsgruppe "Carry over Unerwünschter Stoffe in 
Futtermitteln beim Bundesminister für Verbraucherschutz, Ernährung und Landwirtschaft, "Votum der Arbeitsgruppe zu Möglichkeiten der Minimierung von Mykotoxingehalten in der Fütterung, " 27.03.2002.

http://www.bmelv.de/SharedDocs/Standardartikel/Landw irtschaft/Tier/Futtermittel/CarryOver/AG-CarryOver-Myk otoxin.html

[25] R. B. Harvey, T. D. Phillips, J. A. Ellis, L. F. Kubena, W. E. Huff and H. D. Petersen, "Effects on Aflatoxin M1 Residues in Milk by Addition of Hydrated Sodium Calcium Aluminosilicate to Aflatoxin-Contaminated Diets of Dairy Cows," American Journal of Veterinary Research, Vol. 52, No. 9, 1991, pp. 1556-1559.

[26] “Commission Regulation (EC) № 1881/2006 of 19 December 2006 Setting Maximum Levels for Certain ConTaminants in Foodstuffs," Official Journal of the European Union, Series L, No. 364, 2006, pp. 5-24.

[27] "Verordnung über Diätetische Lebensmittel (Diätverordnung)," vom 28.April 2005, Zuletzt Geändert Durch Art. 1 der 16. ÄndVO vom 01.10.2010, Bundesgesetzblatt I, p. 1306.

[28] "Opinion of the Scientific Panel on Contaminants in the Food Chain on a Request from the Commission Related to Ochratoxin A in food. Question № EFSA-Q-2005154," The EFSA Journal, No. 365, 2006, pp. 1-56.

[29] E. Anli and M. Bayram, "Ochratoxin A in Wines," Food Reviews International, Vol. 25, No. 3, 2009, pp. 214-232. doi:0.1080/87559120902956182

[30] Deutsche Forschungsgemeinschaft (DFG), "Ochratoxin A: Vorkommen und Toxikologische Bewertung," VCH, Weinheim, 1990.

[31] V. Meucci, E. Razzuoli, G. Soldani and F. Massart, "Mycotoxin Detection in Infant Formula Milks in Italy," Food Additives and Contaminant. Part A, Chemistry, Analysis, Control, Exposure \& Risk Assessment, Vol. 27, No. 1, 2010, pp. 64-71.

[32] “Commission Recommendation № 2006/576/EC of 17 August 2006 on the Presence of Deoxyvalenol, ZearaleNone, Ochratoxin A, T-2 and HT-2 and Fumonisins in Products Intended for Animal Feeding," Official Journal of the European Union, Series L, No. 229, 2006, pp. 7-9.

[33] C. J. Mirocha, S. V. Pathre, B. Schauerhamer and C. M. Christensen, "Natural Occurrence of Fusarium Toxins in Feedstuff," Applied and Environmental Microbiology, Vol. 32, No. 4, 1976, pp. 553-556.

[34] F. Chen, Y. Ma, C. Xue, J. Ma, Q. Xie, G. Wang, Y. Bi and Y. Cao, "The Combination of Deoxyvalenol and Zearalenone at Permitted Feed Concentrations Causes Serious Physiological Effects in Young Pigs," Journal of Veterinary Science, Vol. 9, No. 1, 2008, pp. 39-44.

[35] R. R. Rasmussen, I. M. Storm, P. H. Rasmussen, J. Smedsgaard and K. F. Nielsen, "Multi-Mycotoxin Analysis of Maize Silage by LC-MS/MS," Analytical and Bioanalytical Chemistry, Vol. 397, No. 2, 2010, pp. 765-776. doi:0.1007/s00216-010-3545-7

[36] A. Zinedine, J. M. Soriano, J. C. Moltó and J. Manes,
"Review on the Toxicity, Occurrence, Metabolism, DetoXification, Regulations and Intake of Zearalenone: Anoestrogenic Mycotoxin," Food and Chemical Toxicology, Vol. 45, No. 1, 2007, pp. 1-18. doi:0.1016/j.fct.2006.07.030

[37] F. Q. Li, X. Y. Luo and T. Yoshizawa, "Mycotoxins (trichothecenes, Zearalenone and Fumonisins) in Cereals Associated with Human Red-Mold Intoxications Stored Since 1989 and 1991 in China," Natural Toxins, Vol. 7, No. 3, 1999, pp. 93-97.

doi:0.1002/(SICI)1522-7189(199905/06)7:3<93::AID-NT $\underline{45>3.0 . \mathrm{CO} ; 2-5}$

[38] F. Massart and G. Saggese, "Oestrogenic Mycotoxin Exposures and Precocious Pubertal Development," International Journal of Andrology, Vol. 33, No. 2, 2010, pp. 369-376. doi:0.1111/j.1365-2605.2009.01009.x

[39] Scientific Committee on Food, "Opinion of the Scientific Committee on Food on Fusarium toxins. Part 2: Zearalenone (ZEA)," 22 June 2000.

http://ec.europa.eu/food/fs/sc/scf/out65_en.pdf

[40] J. Plasencia and C. J. Mirocha, "Isolation and Characterization of Zearalenone Sulfate Produced by Fusarium spp.," Applied and Environmental Microbiology, Vol. 57, No. 1, 1991, pp. 146-150.

[41] H. Kamimura, "Conversion of Zearalenone to Zearalenone Glycoside by Rhizopus spp.," Applied and Environmental Microbiology, Vol. 52, No. 3, 1986, pp. 515519.

[42] T. Goyarts, D. Dänicke, H. Valenta and K. H. Ueberschär, "Carry-Over of Fusarium Toxins (Deoxynivalenol and Zearalenone) from Naturally Contaminated Wheat to Pigs," Food Additives and Contaminants, Vol. 24, No. 4, 2007, pp. 369380. doi:0.1080/02652030600988038

[43] S. Dänicke, H. Valenta, K. H. Ueberschär and S. Matthes, "On the Interactions between Fusarium Toxin-Contaminated Wheat and Non-Starch-Polysaccharide Hydrolysing Enzymes in Turkey Diets on Performance, Health and Carry-Over of Deoxynivalenol and Zearalenone," British Poultry Science, Vol. 48, No. 1, 2007, pp. 39-48. doi:0.1080/00071660601148161

[44] E. Oldenburg, "Mykotoxine im Grundfutter und ihre Bedeutung im Carry-over-Geschehen," In: Kreisläufe erwünschter und unerwünschter Stoffe-ihre Bedeutung in der Nahrungskette, Informationsveranstaltung der Arbeitsgruppe "Carry over unerwünschter Stoffe in Futtermitteln", Braunschweig, Germany, October 1998. Bundesministerium für Ernährung, Landwirtschaft und Forsten, Eds., Landwirtschaftsverlag, Münster, 1998, pp. 19-31.

[45] W. M. Hagler, G. Danko, L. Horvath, M. Palyusik and C. J. Mirocha, "Transmission of Zearalenone and Its Metabolites into Ruminant Milk," Acta Veterinaria Academiae Scientiarum Hungaricae, Vol. 28, No. 2, 1980, pp. 209-216.

[46] R. V. Bhat, S. R. Beedu, Y. Ramakrishna and K. L. Munshi, "Outbreak of Trichothecene Mycotoxicosis Associated with Consumption of Mould-Damaged Wheat Production in Kashmir Valley, India," Lancet, Vol. 1, No. 8628, 1989, pp. 35-37. doi:0.1016/S0140-6736(89)91684-X 
[47] Y. Luo, T. Yoshizawa and T. Katayama, "Comparative Study on the Natural Occurrence of Fusarium Mycotoxins (Trichothecenes and Zearalenone) in Corn and Wheat from High- and Low-Risk Areas for Human Esophageal Cancer in China," Applied and Environmental Microbiology, Vol. 56, No. 12, 1990, p. 3723.

[48] C. Keese, U. Meyer, H. Valenta, M. Schollenberger, A. Starke, I. A. Weber, J. Rehage, G. Breves and S. Dänicke, "No Carry Over of Unmetabolised Deoxynivalenol in Milk of Dairy Cows Fed High Concentrate Proportions," Molecular Nutrition and Food Research, Vol. 52, No. 12, 2008, pp. 1514-1529. doi:0.1002/mnfr.200800077

[49] D. B. Prelusky, H. L. Trenholm, G. A. Lawrence and P. M. Scott, "Nontransmission of Deoxynivalenol (Vomitoxin) to Milk Following Oral Administration to Dairy Cows," Journal of Environmental Science and Health, Part. B, Pesticides, Food Contaminants and Agricultural Wastes, Vol. 19, No. 7, 1984, pp. 593-609. doi:0.1080/03601238409372453

[50] D. B. Prelusky, D. M. Veira, H. L. Trenholm and B. C. Foster, "Metabolic Fate and Elimination in Milk, Urine and Bile of Deoxynivalenol Following Administration to Lactateing Sheep," Journal of Environmental Science and Health, Part. B, Pesticides, Food Contaminants and Agricultural Wastes, Vol. 22, No. 2, 1987, pp. 125-148. doi:0.1080/03601238709372550

[51] K. Seeling, S. Dänicke, H. Valenta, H. P. van Egmond, R. C. Schothorst, A. A. Jekel, P. Lebzien, M. Schollenberger, E. Razzazi-Fazeli and G. Flachowsky, "Effects of Fusarium Toxin-Contaminated Wheat and Feed Intake Level on the Biotransformation and Carry-Over of Deoxynivalenol in Dairy Cows," Food Additives and Contaminants, Vol. 23, No. 10, 2006, pp. 1008-1010. doi:0.1080/02652030600723245

[52] S. Döll, S. Dänicke and H. Valenta, "Residues of Deoxynivalenol (DON) in Pig Tissue after Feeding Mash or Pellet Diets Containing Low Concentrations," Molecular Nutrition and Food Research, Vol. 52, No. 6, 2008, pp. 727-734. doi:0.1002/mnfr.200700308

[53] D. B. Prelusky, H. L. Trenholm, R. M. G. Hamilton and J. D. Miller, "Transmission of ${ }^{(14} \mathrm{C}^{)}$Deoxynivalenol to Eggs Following Oral Administration to Laying Hens," Journal of Agricultural and Food Chemistry, Vol. 35, No. 2, 1987, pp. 182-186. doi:0.1021/jf00074a004

[54] Scientific Committee on Food, "Opinion on Fusarium Toxins. Part 1: Deoxynivalenol (DON)," Annex VI to the Minutes of the 119th Pleanry Meeting, 2 December 1999. http://www.europa.eu.int/comm/dg24/health/sc/scf/index en.html

[55] Scientific Committee on Food, "Opinion of the Scientific Committee on Food on Fusarium toxins. Part 6: Group Evaluation of T-2 toxin, HT-2 Toxin, Nivalenol and Deoxynivalenol, " 27 February 2002, [12 pp.], $\mathrm{http} / /$ ec.europa.eu/food/fs/sc/scf/out123_en.pdf

[56] R. V. Bhat, P. H. Shetty, R. P. Amruth and R. V. Sudershan, "A Foodborne Disease Outbreak Due to the Consumption of Moldy Sorghum and Maize Containing Fu- monisin Mycotoxins," Journal of Toxicology. Clinical toxicology, Vol. 35, No. 3, 1997, pp. 249-255. doi:0.3109/15563659709001208

[57] B. A. Becker, L. Pace, G. E. Rottinghaus, R. Shelby, M. Misfeldt and P. F. Ross, "Effects of Feeding Fumonisin B1 in Lactating Sows and Their Suckling Pigs," American Journal of Veterinary Research, Vol. 56, No. 9, 1995, pp. 1253-1258.

[58] M. Sabater-Vilar, R. F. M. Maas, H. De Bosschere, R. Ducatelle and J. Fink-Gremmels, "Patulin Produced by an Aspergillus clavatus Isolated from Feed Containing Malting Residues Associated with a Lethal Neurotoxicosis in Cattle," Mycopathologia, Vol. 158, No. 4, 2004, pp. 419-426. doi:0.1007/s11046-005-2877-x

[59] M. A. Mansfield, A. D. Jones and G. A. Kuldau, "Contamination of Fresh and Ensiled Maize by Multiple Penicillium Mycotoxins," Phytopathology, Vol. 98, No. 3, pp. 330-336. doi:0.1094/PHYTO-98-3-0330

[60] G. E. Wood, "Mycotoxins in Foods and Feeds in the United States," Journal of Animal Science, Vol. 70, No. 12, 1992, pp. 3941-3949.

[61] R. Labuda, A. Parich, F. Berthiller and D. Tancinová, "Incidence of Trichothecenes and Zearalenone in Poultry Feed Mixtures from Slovakia," International Journal of Food Microbiology, Vol. 105, No. 1, 2005, pp. 19-25. doi:0.1016/j.ijfoodmicro.2005.06.005

[62] S. Meier, C. Kühn, R. Schnaufer, "Untersuchung von Getreide und Getreidemehlen im Jahr 2009 auf ihren Gehalt an Fusarientoxinen (Deoxynivalenol, Zearalenon, T2und HT2-Toxin)," 26.01.2010.

http://www.untersuchungsämter-bw.de/pub/beitrag.asp?s ubid=1\&Thema_ID $=12 \&$ ID $=1259$

[63] C. Y. Xue, G. H. Wang, F. Chen, X. B. Zhang, Y. Z. Bi and Y. C. Cao, "Immunopathological Effects of Ochratoxin A and T-2 Toxin Combination on Broilers," Poultry Science, Vol. 89, No. 6, 2010, pp. 1162-1166. doi:0.3382/ps.2009-00609

[64] K. Urga, A. Debella, Y. W. Medihn, N. Agata, A. Bayu, W. Zewdie, "Laboratory Studies on the Outbreak of Gangrenous Ergotism Associated with Consumption of Contaminated Barley in Arsi, Ethiopia," Ethiopian Journal of Health Development, Vol. 16, 2002, pp. 317-323.

[65] B. Schumann, P. Lebzien, K. H. Ueberschär and S. Dänicke, "Effects of the Level of Feed Intake and Ergot Contaminated Concentrate on Ergot Alkaloid Metabolism and Carry Over into Milk," Molecular Nutrition and Food Research, Vol. 53, No. 7, 2009, pp. 931-938. doi:0.1002/mnfr.200800319

[66] C. T. Whittemore, R. C. F. Macer, J. K. Miller and P. G. Mantle, "Some Consequences of the Ingestion by Young and Growing Pigs of Feed Contaminated with Ergot," Research in Veterinary Science, Vol. 20, 1976, pp. 61-69

[67] S. Mainka, S. Dänicke, H. Böhme, K. H. Ueberschär, S. Polten and L. Hüther, "The Influence of Ergot-Contaminated Feed on Growth and Slaughtering Performance, Nutrient Digestibility and Carry Over of Ergot Alkaloids 
in Growing-Finishing Pigs," Archives of Animal Nutrition, Vol. 59, No. 6, 2005, pp. 377-395. doi:0.1080/17450390500352970

[68] J. C. Young and R. R. Marquardt, "Effects of Ergotamine Tartrate on Growing Chickens," Canadian Journal of Animal Science, Vol. 62, 1982, pp. 1181-1191. doi:0.4141/cjas82-138

[69] B. Schumann, S. Dänicke, U. Meyer, K. H. Ueberschär and G. Breves, "Effects of Different Levels of Ergot in Concentrates on the Growing and Slaughtering Performance of Bulls and on Carry-Over into Edible Tissues," Archives of Animal Nutrition, Vol. 61, No. 5, 2007, pp. 357-370. doi:0.1080/17450390701556726

[70] J. Wolff, "Bildung von Mykotoxinen auf Getreide und in Getreideerzeugnissen-Bedeutung im Carry-Over-Geschehen," In: Kreisläufe erwünschter und unerwünschter Stoffe-ihre Be deutung in der Nahrungskette, Informationsveranstaltung der Arbeitsgruppe "Carry over unerwünschter Stoffe in Futtermitteln," Braunschweig, Germany, October 1998. Bundesministerium für Ernährung, Landwirtschaft und Forsten, Eds., Landwirtschaftsverlag, Münster, 1998, pp. 208-224.

[71] F. W. McKoen and D. A. Egan, "Lameness in Cattle Fed Ergotised Silage," Irish Veterinary Journal, Vol. 25, 1971, pp. 67-69.

[72] J. Wolff, W. I. F. Richter and B. Spann, "Mutter-kornalkaloide in der Milch?" In: Grünland als Produktionsstandort und Landschaftselement, Vorträge zum Generalthema des 107. VDLUFA Kongresses, Garmisch-Partenkirchen, Germany, September 1994, VDLUFA, Darmstadt, 1995, pp. 521-524.

[73] “Commission Regulation (EC) № 824/2000 of 19 April 2000 Establishing Procedures for the Taking-Over of Cereals by Intervention Agencies and Laying down Methods of Analysis for Determining the Quality of Cereals," $O f$ ficial Journal of the European Union, Series L, No. 100, 20.04.2000, p. 31.

[74] "Opinion of the Scientific Panel on Contaminants in Food Chain on a Request from the Commission Related to Ergot as Undesirable Substance in Animal Feed. Question № EFSA-Q-2003-38," The EFSA Journal, No. 225, 2005, pp. $1-27$.

[75] "Council Directive 1999/29/EC of 22 April 1999 on the Undesirable Substances and Products in Animal Nutrition," Official Journal of the European Community, Series L, No. 115, 04.05.1992, pp. 32-46.

[76] C. Schneider "Vorkommen und Nachweis von Citrinin in Lebensmitteln Pflanzlicher Herkunft," Veterinary Doctoral Dissertation, Ludwigs-Maximilians-Universität, München, 2007.

[77] A. Bernhoft, M. Keblys, E. Morrison, H. J. Larsen and A. Flaoyen, "Combined Effects of Selected Penicillium Mycotoxins on in Vitro Proliferation of Porcine Lymphocytes," Mycopathologia, Vol. 158, No. 4, 2004, pp. 441-450.

\section{doi:0.1007/s11046-004-2843-z}

[78] A. M. Abdelhamid and T. M. Dorra, "Study on Effects of Feeding Laying Hens on Separate Mycotoxins (Aflatoxins, Patulin, or Citrinin)-Contaminated Diets on the Egg Quality and Tissue Constituents," Archiv für Tierernährung, Vol. 40, No. 4, 1990, pp. 305-316. doi:0.1080/17450399009430927

[79] G. Díaz-Llano and T. K. Smith, “The Effect of Feeding Grains Naturally Contaminated with Fusarium Mycotoxins with and without a Polymeric Glucomannan Adsorbent on Lactation, Serum Chemistry, and Reproductive Performance after Weaning of First-Parity Lactating Sows," Journal of Animal Science, Vol. 85, No. 6, 2007, pp. 1412-1423. doi:0.2527/jas.2006-213

[80] S. D. Stoev, M. F. Dutton, P. B. Njobeh, J. S. Mosonik and P. A. Steenkamp, "Mycotoxic Nephropathy in Bulgarian Pigs and Chickens: Complex Aetiology and Similarity to Balkan Endemic Nephropathy," Food Additives and Contaminants, Part A, Chemistry, Analysis, Control, Exposure \& Risk Assessment, Vol. 27, No. 1, 2010, pp. 72-88.

[81] M. Carvajal, F. Rojo, I. Mendez and A. Bolanos, "Aflatoxin B1 and Its Interconverting Metabolite Aflatoxicol in Milk: The Situation in Mexico," Food Additives and Contaminants, Vol. 20, No. 11, 2003, pp. 1077-1086. doi:0.1080/02652030310001594478

[82] L. W. D. Raamsdonk, J. C. H. van Eijkeren, G. A. L. Meijer, M. Rennen, M. J. Zeilmaker, L. A. P. Hoogenboom and M. Mengelers, "Compliance of Feed Limits Does Not Mean Compliance of Food Limits," Biotechnology, Agronomy, Society and Environment, Vol. 13, 2009, pp. 51-57.

[83] A. Prandini, G. Tansini, L. Filippi, M. Laporta and G. Piva, "On the Occurrence of Aflatoxin M1 in Milk and Dairy Products," Food and Chemical Toxicology, Vol. 47, No. 5, 2009, pp. 984-991. doi:0.1016/j.fct.2007.10.005

[84] B. Dashti, S. Al-Hamli, H. Alomirah, S. Al-Zenki, A. B. Abbas and W. Sawaya, "Levels of Aflatoxin M1 in Milk, Cheese Consumed in Kuwait and Occurence of Total Aflatoxin in Local and Imported Animal Feed," Food Control, Vol. 20, No. 7, 2009, pp. 686-690. doi:0.1016/j.foodcont.2009.01.001

[85] W. B. Shim, B. B. Dzantiev, S. A. Eremin and D. H. Chung, "One-Step Simultaneous Immunochromatographic Strip Test for Multianalysis of Ochratoxin A and Zearalenone," Journal of Microbiology and Biotechnology, Vol. 19, No. 1, 2009, pp. 83-92.

[86] M. W. Trucksess, C. M. Weaver, C. J. Oles, F. S. Fry Jr. and G. O. Noonan, "Determination of Aflatoxins B1, B2, G1, and G2 and Ochratoxin A in Ginseng and Ginger by Multitoxin Immunoaffinity Column Clean up and liquid Chromatographic Quantitation: Collaborative Study," Journal of AOAC International, Vol. 91, No. 3, 2008, pp. 511523. 